\title{
REPRESENTAÇÕES ACERCA DA VELHICE ENTRE IDOSOS DO LAR FREI FABIANO DE CRISTO
}

\author{
RogÉRIO DA PALMA ${ }^{1}$ \\ https://orcid.org/0000-0002-9848-1791 \\ SAMANTA VALÉRIO RAMOS ${ }^{2}$ \\ https://orcid.org/0000-0002-5364-7268
}

\begin{abstract}
Resumo: $\mathrm{O}$ artigo pretende expor os resultados das atividades de extensão realizadas entre os anos de 2015 e 2017 no Lar do Idoso Frei Fabiano de Cristo, situado em Amambai/MS. Realizou-se atividades recreativas e entrevistas junto ao público alvo, assim como a leitura de referências bibliográficas. Percebeu-se que, sob uma heterogeneidade de termos e rótulos, tais como Terceira Idade, idoso, velhice, "melhor idade", também se apresentam uma heterogeneidade de condições sociais, físicas e psicológicas. Conseguiu-se perceber que o processo de envelhecimento, embora muitas vezes caracterizado somente pela existência de mudanças físicas e biológicas, também está relacionado a uma série de questões culturais, políticas e econômicas. De um modo geral, pôde-se analisar as representações sociais que esses idosos transmitem acerca da velhice.
\end{abstract}

Palavras-chave: Lar do Idoso. Representação. Envelhecimento.

\section{REPRESENTATIONS ABOUT THE OLD AGE BETWEEN ELDERIES FROM HOME OF THE ELDERY FREI FABIANO OF CHRIST}

Abstract: The article intends to expose the results of the extension activities carried out between the years of 2015 and 2017 in the Home of the Elderly Frei Fabiano de Cristo, located in Amambai / MS. There were recreational activities and interviews with the target audience, as well as the reading of bibliographical references. It was noticed that, under a heterogeneity of terms and labels, such as the Third Age, elderly, old age, "better age", there is also a heterogeneity of social, physical and psychological conditions. It has been realized that getting older process, although often characterized only by the existence of physical and

1 Doutor em Sociologia pela UFSCar. Professor Adjunto da UEMS/Amambai. E-mail: rpalma@ uems.br.

2 Licenciada em Ciências Sociais pela UEMS/Amambai. E-mail: Samanta_2209@hotmail.com. 
biological changes, is also related to several of cultural, political and economic issues. In general, we could analyze the social representations that these elders transmit about old age. Keywords: Home of the eldery. Representation. Getting older.

\section{REPRESENTACIONES ACERCA DE LA VELHICE ENTRE EDADES DEL LAR FREI FABIANO DE CRISTO}

Resumen: El artículo pretende exponer los resultados de las actividades de extensión realizadas entre los años de 2015 y 2017 en el Hogar del Anciano Fray Fabiano de Cristo, situado en Amambai / MS. Se realizaron actividades recreativas y entrevistas junto al público objetivo, así como la lectura de referencias bibliográficas. Se percibió que, bajo una heterogeneidad de términos y rótulos, tales como Tercera edad, anciano, vejez, "mejor edad", también se presentan una heterogeneidad de condiciones sociales, físicas y psicológicas. Se logró percibir que el proceso de envejecimiento, aunque muchas veces caracterizado sólo por la existencia de cambios físicos y biológicos, también está relacionado a una serie de cuestiones culturales, políticas y económicas. En general, se pudo analizar las representaciones sociales que estos ancianos transmiten acerca de la vejez.

Palabras clave: Hogar Del Anciano. Representacion. Edad.

Submetido em: 01/12/2018

Aceito em: 20/12/2018.

\section{INTRODUÇÃO}

De acordo com os dados oficiais, a população considerada idosa cresce de maneira acelerada. Entre os anos de 1980 e 2000, a população mundial com mais de 60 anos cresceu 7,3 milhões. De acordo com o Instituto Brasileiro de Geografia e Estatística - (IBGE), o Brasil possui, atualmente, mais de 26 milhões de pessoas - 13\% da população total - com idade a partir de 60 anos, ou seja, aqueles que são classificados institucionalmente como idosos. Segundo dados da Organização Mundial de Saúde (OMS), até o ano de 2025, o Brasil será o sexto país do mundo em número de idosos. Podemos perceber que o processo de envelhecimento, embora muitas vezes caracterizado somente pela existência de mudanças físicas e biológicas, também está relacionado a uma série de questões culturais, políticas e econômicas. São múltiplos os desafios trazidos pelo envelhecimento populacional, desde problemas econômicos e fiscais até aqueles situados na área de saúde pública. A necessidade de se formular e implementar políticas públicas voltadas especificamente para esse segmento populacional torna-se, portanto, algo necessário. 
[...] chefe do programa de envelhecimento da Organização Mundial de Saúde (OMS), o brasileiro Alexandre Kalache, alerta que está em curso uma enorme mudança de paradigmas, provocada pelo aumento da longevidade, acompanhado de uma redução das taxas de fecundidade. "Até o início dos anos 2000, esse quadro ainda não estava tão claro", lembra ele, apontando que o fenômeno é recente e vai exigir uma mudança profunda nos costumes. (FARELO; VIEIRA, 2007, p. 3).

$\mathrm{O}$ artigo busca analisar as condições sociais de um grupo de idosos durante a participação de atividades recreativas e educacionais desenvolvidas no Lar do Idoso Frei Fabiano de Cristo, situado em Amambai/MS. Essa instituição abriga, atualmente, 40 idosos. Alguns se encontram em bom estado físico e mental, outros acamados (ou na situação de cadeirantes) e/ou com algum tipo de distúrbio psicológico. A maioria desses idosos já morava no próprio município, enquanto que outros foram transferidos de outras cidades da região, como Coronel Sapucaia. O Lar é sustentado pela Prefeitura Municipal de Amambai e conta com a ajuda das aposentadorias dos abrigados e também de doações dos moradores locais.

Realizou-se atividades recreativas e entrevistas junto ao púbico alvo, assim como a leitura de referências bibliográficas. Percebeu-se que, sob uma heterogeneidade de termos e rótulos, tais como Terceira Idade, idoso, velhice e "melhor idade", também se apresentam uma heterogeneidade de condições sociais, físicas e psicológicas. A realização deste trabalho ocorreu no âmbito do curso de Ciências Sociais da Universidade Estadual de Mato Grosso do Sul, em parceria com o projeto de extensão A cidadania ao envelhecer: o Lar do Idoso Frei Fabiano de Cristo (Amambai/MS), durante os anos de 2015 a 2017. De um modo geral, pôde-se analisar as representações sociais que esses idosos transmitem acerca da velhice.

\section{AS COMPLEXIDADES DO ENVELHEGIMENTO: PARA ALÉM DE UMA CONCEPÇÃO PURAMENTE BIOLÓGICA}

Em termos conceituais, pode-se afirmar que há uma diferença envelhecimento e velhice:

Envelhecimento: processo evolutivo, um ato contínuo, isto é, sem interrupção, que acontece a partir do nascimento do indivíduo até o momento de sua morte [...] é o processo constante de transformação. Velhice: é o estado de ser velho, o produto do envelhecimento, o resultado do processo de envelhecer. (COSTA, 1998, P. 26) 
Podemos entender a velhice como sendo caracterizada pela existência de mudanças físicas, mas sem esquecer os fatores socioculturais que influenciam e, em certos, definem esse estado. De acordo com a perspectiva sociológica, é o contexto social que cria determinadas categorias e as classifica. Termos como Terceira Idade, por exemplo, devem primeiramente ser entendidos como resultado de diversas práticas sociais e necessidades organizacionais.

Percebe-se que, atualmente, o envelhecimento pode conter aspectos biológicos, psicológicos e sociológico. A idade biológica está relacionada às mudanças sofridas durante o processo de envelhecimento, já a idade psicológica está relacionada com as consequências comportamentais do ambiente em que vive o idoso, enquanto a idade social é determinada pela e história e vivencia que o idoso carrega consigo. Quando falamos em infância, adolescência, maturidade e velhice, na verdade, pensamos na elaboração simbólica de um processo biológico, com elementos culturais e históricos de uma determinada sociedade. A maneira como esses períodos são vistos pela sociedade, a posição que nela ocupam o tratamento que lhes é dispensado pelas demais gerações, são determinados pelos contextos históricos, políticos e econômicos em que vive cada cultura (DEBERT, 1994).

Segundo Simone de Beauvoir (1990), não é fácil descrever uma definição para a velhice, especialmente quando se leva em conta a estreita interdependência dos pontos de vista biológicos, psicológicos e sociais que circundam o indivíduo. Pode-se dizer que a velhice deve ser vista, portanto, como um contexto em que as "idades da vida" se tornaram mais claramente delimitadas. Como um processo para a demarcação não apenas da velhice, mas de outras categorias, como a infância e juventude, que se tornaram objetos de práticas e processos institucionais específicos (KATZ, 1996).

De acordo com Guita Debert, a velhice não é uma categoria natural.

[...] a idade não é um dado da natureza, não é um princípio naturalmente constitutivo de grupos sociais, nem o fator explicativo dos comportamentos humanos. Essa demonstração exige um rompimento com os pressupostos da psicologia do desenvolvimento que concebe o curso da vida como uma sequência unilinear de etapas evolutivas em que cada etapa, apesar das particularidades sociais e culturais, seriam estágios pelos quais todos os indivíduos passam e, portanto, teriam caráter universal (DEBERT, 1998, p. 9). 
A velhice, portanto, é uma construção social e produção histórica, assim como os demais tempos da vida, onde uma série de mudanças específicas gera condições para o surgimento dessa "nova fase" conhecida como "velhice".

A velhice, assim como a infância e a juventude, não tratam de características biológicas que ocorrem igualmente em todos os indivíduos com o passar dos anos. Pierre Bourdieu (1983, apud DEBERT, 1998), em seu texto A Juventude é apenas uma palavra, esclarece que a manipulação das categorias de identidade envolve uma verdadeira luta política, onde o que está em jogo é a redefinição de poderes ligados a grupos sociais distintos em variados momentos no ciclo da vida. A categoria velhice é resultado de lutas entre grupos sociais; são relações de força onde cada geração luta pela distribuição de poder e privilégios entre elas.

\begin{abstract}
A invenção da "infância", da "adolescência" e, mais recentemente, da "primeira infância", resultam, em grande parte, do prolongamento da duração dos estudos e da difusão da escola maternal. Da mesma forma, atualmente, a invenção da "terceira idade", essa nova etapa do ciclo da vida que tende a se intercalar entre aposentadoria e velhice, é, no essencial, o produto da generalização dos sistemas de aposentadoria e da intervenção correlativa das instituições e agentes que, ao se especializarem no tratamento da velhice, contribuem para o processo de autonomização da categoria e, ao mesmo tempo, da população designada por ela (LENOIR,1996, p. 76).
\end{abstract}

Nas sociedades capitalistas ocidentais, o idoso/velho muitas vezes perde o seu reconhecimento social, passando a ser classificado como um incômodo, exatamente por deixar de ser produtivo. Ainda que essa mesma sociedade crie rótulos positivos para essa fase da vida, tal como "melhor idade", eles perpassam por uma ideologia do consumo, criando representações sociais de um idoso supostamente mais dinâmico, preocupado com o lazer e em estabelecer relações sociais, enfim, querendo envelhecer com mais qualidade de vida. Entre todas diversas perspectivas, no entanto, parece haver uma preocupação, demonstrada de forma muitas implícita: a perda da autoestima está presente na maioria dos indivíduos que estão entrando ou já se encontram na fase da "melhor idade".

A "velhice" como problema social surgiu, antes de tudo, na classe operária pelo fato da extensão rápida, sobretudo a partir de meados do século XIX, da organização do capitalismo do trabalho e do sistema de atitudes que lhe é associado. Presume-se que o salário remunera apenas a força investida no trabalho [...] a "velhice" dos operários é, então, assimilada, pelo patronato capitalista, à "invalidez", isto é, à "incapacidade" para produzir. [...] Foi 
a partir dessa lógica que as caixas de aposentadoria foram instituídas pelos empresários a fim de reduzirem os custos da produção, desfazendo-se em condições honrosas dos trabalhadores idosos que ganhavam demais pelo rendimento fornecido (LENOIR, 1996, p. 79).

Enquanto cientistas sociais, é necessário analisar o fenômeno da velhice enquanto um fenômeno social.

As formas de pressão se traduzem em formas de expressão. Na transformação do envelhecimento em problema social estão envolvidas novas definições de velhice e do envelhecimento, que ganham dimensão com a expressão Terceira Idade [...]. O discurso sobre a Terceira Idade, assim, não acompanha simplesmente processos de mudanças objetivas. Pelo contrário, ele deve ser entendido como parte constitutiva dessas mudanças. Contribui para acelerar e direcionar processos, na medida em que opera reclassificações que são constitutivas das formas de gestão do envelhecimento (DEBERT, 1998, p. 23).

Um fator que influencia a qualidade de vida do idoso está associado, necessariamente, aos inúmeros desafios contemporâneos que os idosos enfrentam com a fragilização dos seus laços familiares. Debert (1999) chama esse processo de 'socialização do envelhecimento', considerando a contribuição de outros fatores para a construção da velhice como um problema social.

No processo de constituição da "terceira idade", como problema social - e apesar de tomar uma outra forma - encontramos um trabalho coletivo de imposição de uma identidade social e específica. No entanto [...] emanou não tanto de associações de defesa dos aposentados ou das pessoas idosas [...] mas das diferentes categorias de profissionais da gestão da velhice (trabalhadores e animadores sociais, gerontólogos, geriatras, etc.). Com efeitos, são eles [...] que assinalam a existência do "grupo" e, ao mesmo tempo, a importância política do problema que ele coloca (LENOIR, 1996, p. 89).

O conceito de Terceira Idade também exige do idoso uma constante adaptação a novas situações, como um novo lar (ou casa de repouso), pois grande parte desses idosos possui dificuldade física, mental, além do sedentarismo e morte social, apresentando quadros depressivos, diminuindo assim, a autoestima.

[...] Embora muitas vezes a família tenha dificuldades em aceitar e entender o envelhecimento de um ente, tornando o relacionamento familiar mais difícil. O indivíduo idoso perde a posição de comando e decisão que estava acostumado a exercer e as relações entre pais e filhos modificam-se. Consequentemente as pessoas idosas tornam-se cada vez mais dependentes e uma reversão de papéis estabelece-se. Os filhos geralmente passam a ter 
responsabilidade pelos pais, mas muitas vezes esquece-se de uma das mais importantes necessidades: a de serem ouvidos. Os pais, muitas vezes, quando manifestam a vontade de conversar, percebem que os filhos não têm tempo de escutar as suas preocupações. $\mathrm{O}$ ambiente familiar pode determinar as características e o comportamento do idoso (MENDES, 2005, s/p).

\section{ATIVIDADES RECREATIVAS E SEUS BENEFÍCIOS}

Realizamos junto ao público alvo, os idosos situados no Lar do Idoso Frei Fabiano de Cristo, diversas atividades recreativas, tais como jogar dominó, pintura em sabonetes, confecção de caixas em MDF, desenho com lápis de cor, etc. As atividades foram desenvolvidas quinzenalmente, aos sábados no período vespertino. Segundo Lorda (2001), o idoso é socialmente considerado pouco importante, pois, supostamente, o "velho" se tornou alguém incapaz de lidar com problemas associados a sociedade. Diante disso, surgem diversos problemas: a dependência, a perda de status social e o sentimento de impotência, na maior parte das vezes torna-se um problema.

Percebeu-se que as atividades recreativas podem funcionar como um elemento que eleva a autoestima dos idosos.

A recreação faz parte do lazer, sendo uma atividade física ou mental, onde as atividades são provenientes de motivação interior, com características psico, físico, emocional, promovendo o equilíbrio, pois preserva ou restaura a integridade do organismo. (SANTINI, 1993).

Durante três anos, tivemos a oportunidade de participar ativamente da vida de cada idoso que reside no Lar do Idoso Frei Fabiano de Cristo, tendo vista que, durante as atividades recreativas desenvolvidas no Lar, conseguimos perceber uma grande evolução pessoal dos idosos. Não somente no que diz respeito à sua saúde física, mas também na integração do idoso com seu ambiente social, auxiliando no desenvolvimento da autoestima idoso e na comunicação com os outros asilados.

Um dos papéis atribuídos aos mais velhos é o da arte de contar histórias de um passado considerado longínquo, seja da família, da cidade ou de acontecimentos que marcaram uma determinada geração. Diz-se do idoso que eles são saudosistas, vive das memórias de anos dourados de sua juventude e sempre as evoca para confrontar o passado com os 
contornos do contemporâneo, muitas vezes valorizando o pretérito em detrimento do presente (CORREA; FRANÇA, 2008, p.13).

As atividades recreativas, desenvolvidas com os idosos no Lar, tiveram como principal prioridade conhecer as necessidades e delimitações de cada um, mas, acima de tudo, as atividades se tornaram divertidas, obtendo o principal objetivo, proporcionar alegria e prazer aos idosos.

A recreação ajuda ao idoso a comunicar-se melhor com os outros e a enriquecer a relação que este idoso mantém com o ambiente que o cerca e as atividades devem ser desenvolvidas, considerando sempre sua capacidade física e as necessidades, interesses e motivação que ele apresente. (GEIS, p. 27).

Sendo assim, as atividades recreativas para os idosos foram atraentes, com materiais diversos, para estimular os sentidos, e adaptadas para tal idade, favorecendo o contato social entre os envolvidos. As atividades foram geralmente desenvolvidas em grupos, possibilitando ao idoso se sentir integrado socialmente. De acordo com Maria Ferreira (2001), a recreação não tem limites e idade, mas sim a característica de livre escolha, com intuito de proporcionar alegria e prazer aos idosos. Resumindo, há a impressão que as atividades recreativas, ao suscitar um papel ativo dos idosos, possibilitam que eles, pelo menos momentaneamente, escapem dos estereótipos negativos associados à velhice.

\section{AS REPRESENTAÇÕES ACERCA DA VELHICE}

Durante as atividades, também pudemos realizar entrevistas com alguns idosos. Realizamos perguntas relacionadas ao sentimento da velhice e a situação na qual se encontravam dentro do Lar. Para muitos, há uma dificuldade em se falar do envelhecimento, pois, muitas vezes, ele está associado à perda da autonomia - sobre o próprio corpo, de mobilidade, de participação nas decisões sobre a própria vida.

"Ser velho é difícil... É ruim, eu não gosto, sinto falta de quando era nova. A gente vive aqui no lar porque é o jeito, mas se eu pudesse não ficava aqui não. Vivo aqui porque não tive filhos, não tenho mais família" (Dona Z.S, feminino, 77 anos, aposentada).

"Eu gosto daqui, aqui no lar as moças são "boazinhas", vou nos bailes da terceira idade, me sinto bem lá. Gosto quando vocês jovens vem no lar fazer 
atividades, me sinto bem e ativa, me faz lembrar da minha juventude essas atividades" (Dona M., feminino, 67 anos, aposentada).

"Vivo no Lar já fazem 7 anos, até hoje não gosto daqui, meu filho vem as vezes me ver e traz meu neto, disse que vai me levar para morar com ele só não sei quando. Eu não gosto dessas atividades, depois que tive o AVC tudo fica difícil de fazer" (L.S, masculino, 79 anos, aposentado).

"Eu graças a Deus estou bem, não me sinto velha, gosto de me arrumar para o baile da terceira idade, e quero me casar. Tenho dois filhos mas faz muito tempo que não os vejo, devem estar bem" (M.A, feminino, 65 anos, aposentada).

Percebemos nas entrevistas que, dos quatro idosos entrevistados, dois deles associaram a velhice a uma fase ruim da vida, devido ao estado de saúde e suas limitações. Os outros, mesmo enxergando a situação atual como positiva, remetem a prática de atividades recreativas à juventude, muitas vezes negando se sentirem velhas, o que somente reforça os estereótipos negativos vinculados ao envelhecimento.

O velho versus o idoso; a aceitação versus a negação da velhice, culminando no desejado versus o não desejado na velhice. Conclui-se que as pessoas, na continuidade da vida, não querem ser velhas (viver o indesejado, com mal-estar), mas tornarem-se idosas (envelhecer com bem-estar), permitindo compreender o que existe no processo de aceitação e negação da velhice. (NERI, 1995, p.34).

Segundo a Organização Mundial da Saúde (OMS, 2005), a qualidade de vida se caracteriza como o início da percepção do indivíduo na sua posição social e cultural. Qualidade de vida é ter uma vida ativa, saudável e com expectativas, mas, para que isso seja possível, é necessário a prática diária de atividades recreativas, como a dança, ou até mesmo jogar dominó. Segundo o conceito de Araújo (apud MEDEIROS 1999, p.32), qualidade de vida do idoso é: "uma variável resultante do desenvolvimento pessoal e coletivo, dependente de múltiplos fatores, que determinam nossa capacidade de produzir resultados, ser feliz e ser saudável".

Um dos fatores preocupantes na qualidade de vida do idoso, o qual foi destacado nas falas dos entrevistados, é a não aceitação dessa nova fase da vida. $\mathrm{O}$ envelhecimento acaba provocando atitudes como o isolamento, evitando o contato com pessoas da família e amigos, pois o idoso já não se vê presente e ativo dentro do seu círculo de relações. O convívio social trazido pelas 
atividades recreativas pode, nesse sentido, auxiliar na criação de uma auto imagem positiva entre os idosos.

O envelhecer e o estado de ser velho, até hoje, embora em menor proporção, ainda é um tema muito difícil de ser encarado. É quase como se fosse uma praga, uma doença, um mal, seja para aqueles que são jovens, para aqueles que estão começando a envelhecer, ou mesmo para os que já se encontram na própria senescência. É difícil para a maioria das pessoas aceitar o seu próprio envelhecimento. E, para muita gente, felizmente, ter 50 anos é ainda ser e estar jovem (COSTA, 1998, p.17).

A tão buscada qualidade de vida entre os idosos perpassa, nesse sentido, por múltiplos fatores, que vão além da saúde biológica do corpo, mas que depende de aspectos culturais e políticos.

O termo abrange muitos significados, que refletem conhecimentos, experiências e valores de indivíduos e coletividades que a ele se reportam em variadas épocas, espaços e histórias diferentes, sendo portanto uma construção social com a marca da relatividade cultural. (MINAYO et al, 2000, p. 08).

\section{CONSIDERAÇÕES FINAIS}

Através das ações de extensão foi possível conhecer a percepção dos idosos em torno da velhice e do envelhecimento, a fim de entender suas perspectivas e como eles veem essa nova fase da vida, partindo do pensamento de que a velhice (e sua heterogeneidade) é uma categoria social e cultural construída diariamente. Para os idosos que participaram das atividades, a perda da autonomia é quase sempre algo referenciado à velhice. Percebemos, também, que alguns desses idosos valorizam e aceitam a fase do envelhecimento, mas sempre relacionam suas mobilidades (idas aos bailes e à casa de familiares) e atividades (tais como música, jogos, danças, brincadeiras etc.) com um sentimento de juventude, negando a condição de idoso.

A velhice constitui-se em um estágio do desenvolvimento humano e, assim como nas outras etapas, as pessoas vivenciam um conjunto de perdas e ganhos. Entretanto, a ideia de incapacidade, doença, afastamento e dependência ainda prevalece nas imagens sobre a velhice (FREIRE, 2000, p.16). 
Através das representações sociais acerca da velhice, presentes nos discursos dos idosos, pudemos concluir que o desenvolvimento de atividades recreativas traz benefícios consideráveis para a autoestima dos asilados. Sendo a velhice quase sempre vinculada à perda de autonomia e da capacidade de realização de determinadas ações, é possível afirmar que tais atividades fomentam uma experiência de sujeito em indivíduos que, uma vez asilados, vivenciam constantemente uma situação de dependência e tutela.

\section{REFERÊNCIAS}

BEAUVOIR, Simone de. A Velhice. Tradução de Maria Helena Franco Monteiro. Rio de Janeiro: Nova Fronteira, 1990.

BRANDEN, N. Autoestima, como aprender a gostar de si mesmo. 39 ed. São Paulo: Saraiva, 2001.

BOSI, Ecléa. Memória e Sociedade: Lembranças de Velhos. Rio de Janeiro: Companhia das Letras, 1994.

MOTTA, A. "Chegando pra idade". In: BARROS, M. (organizadores). Velhice ou terceira idade? Rio de Janeiro: Fundação Getúlio Vargas, 1998. p. 223-35.

CAVALLARI, V.R.; ZACHARIAS, V. Trabalhando com recreação. 6. ed. São Paulo: Ícone, 2003.

CORREA, R. M. e FRANÇA, M. A. S. Memória e Experiência Narrativa com Idosos. Unesp - Faculdade de ciências e letras de Assis, 2018.

COSTA, E. M. S. Gerontodrama: a velhice em cena. São Paulo: Ágora, 1998.

DEBERT, G. G. "Pressupostos da reflexão antropológica sobre a velhice". In: DEBERT, G.G. (Org.). Antropologia e velhice. Campinas: IFCH/UNICAMP, 1998, p. 7-27. (Textos Didáticos).

DEBERT, G.G. (Org.). Velhice e sociedade. Campinas: Papirus, 1999, p. 141-178.

FERREIRA, M. L. M. "Memória e velhice: do lugar da lembrança”. In: Lins de Barros, Myriam Moras (org). Velhice ou terceira idade? 3 eds. Rio de Janeiro: FGV, 2001.

FRIAS MAE, Paranhos WY, Fera P, Souza SV, Pintan LF. "A contribuição da recreação para a qualidade de vida do idoso". Science in Health. 2011; 2(3):155-62.

FONSECA DA SILVA, Viviane Cristina, Figueiroa de Medeiros, Bartolomeu, de Brito, Ana Maria, Um olhar sobre o processo do envelhecimento: a percepção de idosos sobre a velhice. Revista Brasileira de Geriatria e Gerontologia, 2006.

GIL, A. C. Métodos e técnicas de pesquisa social. 4. ed. São Paulo: Atlas, 1994.

INSTITUTO BRASILEIRO DE GEOGRAFIA E ESTATÍSTICA (IBGE). Síntese de 
Indicadores Sociais 2008. Disponível em: http://www.ibge.gov.br/home/estatistica/populacao/condicaodevida/indicadoresminimos/sinteseindicsociais2008/default.shtm. Acesso em: 17 out. 2018.

LORDA, C.R; SANCHEZ, C.D. Recreação na 3ª Idade. 3.ed.Rio de Janeiro: Sprint, 2001. LANG, Alice Beatriz da Silva Gordo; CAMPOS, Maria Christina Siqueira de Souza; DEMARTINI, Zeila de Brito Fabri. História Oral, Sociologia e Pesquisa: a abordagem do CERU. São Paulo: Humanitas; CERU, 2010.

MEDEIROS, Aline Carolina. Qualidade de Vida: Um desafio para os aposentados da CELESC. Trabalho de Conclusão de Curso - Serviço Social. UFSC, 1999.

MINAYO, Maria Cecília S.; HARTZ, Z.M.A; BUSS, P.M. Qualidade de vida e saúde: um debate necessário. Ciência e Saúde Coletiva, v.5, nº 1, pp.7-18, 2000.

MINAYO, Maria. C. S. Ciência, técnica e arte: o desafio da pesquisa social. In: MINAYO, Maria. C. S (Org.). Pesquisa social: teoria, método e criatividade. Petrópolis, RJ: Vozes, 2001. p.22.

NERI, L. A. Psicologia do Envelhecimento: Temas selecionados na perspectiva de curso de vida. Campinas: Papirus, 1995.

ORGANIZAÇÃO MUNDIAL DE SAÚDE. Divisão de Saúde Mental Grupo WHOQOL. Versão em português dos instrumentos de avaliação de qualidade de vida (WHOQOL). OMS, 2005. 